\title{
Motivating Management: Corporate Compliance in Environmental Protection*
}

\author{
NEIL A. GUNNINGHAM, DOROTHY THORNTON, and \\ ROBERT A. KAGAN
}

\begin{abstract}
Based on interviews with facility managers in the electroplating and chemical industries, this study examines regulated firms' perceptions of how various instrumental, normative, and social factors motivated their firms' environmental actions. We found that "implicit general deterrence" (the overall effect of sustained inspection and enforcement activity) was far more important than either specific or general deterrence, and that deterrence in any form was of far greater concern to small and medium-sized enterprises than it was to large ones. Most reputationsensitive firms in the environmentally sensitive chemical industry chose to go substantially beyond compliance for reasons that related to risk management and to the perceived need to protect their social license to operate. Almost half our respondents also provided normative explanations for why they complied. Overall, we conclude that there are various, often interwoven, strands that must be taken into account in understanding what motivates corporate environmental behavior. and how they play out depends very much on the size and sophistication of companies themselves and on the characteristics of the industry sector within which they are located.
\end{abstract}

\section{INTRODUCTION}

Most regulatory policymakers and officials, at least in the United States, believe that strong legal punishment of serious and willful violations serves a vital "general deterrence" function. Underlying this view is the assumption that regulated business corporations are "amoral calculators" (Kagan \& Scholz

\footnotetext{
* This paper is part of a broader project funded by the EPA's Science to Achieve Results (STAR) Program, managed by the EPA's Office of Research and Development (ORD), National Center for Environmental Research (NCER). STAR research supports the Agency's mission to safeguard human health and the environment. The authors are grateful to Manuel Vallee and Pete Younkin for their excellent research support throughout the project, and in particular for Manuel's considerable contribution to the interviews and his critique of an early draft. The authors also benefited from comments from participants at a workshop held at the University of California, Berkeley on 2 July 2003 on "Corporate Environmental Performance and the Effectiveness of Government Interventions." We are particularly grateful for the comments of Peter May, both at the workshop and subsequently.

Address correspondence to Neil Gunningham, REGNET, University House, Australian National University, Canberra ACT 0200, Australia; e-mail: neil.gunningham@anu.edu.au.
} 
1984) that take costly measures to meet public policy goals only when (1) specifically required to do so by law, and (2) they believe that legal noncompliance is likely to be detected and harshly penalized (Becker 1968; Miller \& Anderson 1986; Regens, Seldon \& Elliot 1997; Stigler 1970). Yet research in various areas of social regulation indicates that the link between general deterrence and compliance is complex. Regulated business firms' perceptions of legal risk play a far more important role in shaping firm behavior than the objective likelihood of legal sanctions (Simpson 1990: chap. 2). In one of the best studies, Braithwaite and Makkai (1991: 35) found that in the case of nursing home regulation, there was virtually no correlation between facilities' regulatory compliance rates and their perceptions of the certainty and severity of punishment for violations, except for certain minorities of actors in some contexts. ' Regulated enterprises' motivations to comply with regulatory requirements have been found to stem from a wide variety of other factors, including a general belief in the legitimacy of regulatory requirements (Tyler 1990), perceived social costs, shame, or guilt (Grasmick \& Bursik 1990), and informal sanctions inflicted by local communities, NGOs, and others (Gunningham, Kagan \& Thornton 2003; OECD 2000; Vandenbergh 2003).

These findings raise fundamental questions about the salience and functions of general deterrence in regulatory settings. First, in stimulating compliance by regulated businesses, how salient and important are the "general deterrence" messages sent by formal legal sanctions against other firms, compared to (a) the "specific deterrence" engendered by inspections of, and legal sanctions against, the firm itself, (b) the "implicit deterrence" message sent simply by the dissemination of governmental regulations, (c) the threat of informal economic and social sanctions, and (d) normative commitments to comply with laws and regulations? Second, do motivations to comply (and the salience of general deterrence) vary across firms-depending for example, on the type and size of organization (Gray \& Scholz 1991: 185-214), or the characteristics of particular industry sectors?

One perspective on these questions is provided by a related article in this Special Issue of Law \& Policy (Thornton, Gunningham \& Kagan 2005), in which we report the results of our survey of $233 \mathrm{firms}$ in eight industries. In each of those eight industries, at least one firm (not including any in our sample) had recently been the subject of a serious legal penalty for violating U.S. environmental law. The survey findings suggested that most respondents did not follow closely and remember news of legal sanctions against other firms in their industry, carefully calculating their responses accordingly-as would be predicted by what we labeled "explicit general deterrence" theory. Yet there was some support for what we labeled "implicit general deterrence" - the sense that the mere existence of official regulations entails both some risk of punishment and a duty to comply. Thus almost all respondents could remember some salient legal actions against some firms at some time in the past. And a majority reported that hearing about legal sanctions against other firms had prompted them to review, and often to take further action 
to strengthen, their own firm's environmental program. For most respondents, hearing about sanctions against other firms had primarily a "reminder" and "reassurance" function-reminding them to review their own compliance status and reassuring them that if they invested in compliance efforts, their competitors who cheated would probably not get away with it.

This article reports on a second phase of the same research project. This phase entailed longer, more in-depth interviews with industrial facility managers in the electroplating and chemical industry-two of the eight industries that were the focus of the 233 firm survey. Through these interviews, we sought to delve more deeply into regulated firms' perceptions of the role of general deterrence, specific deterrence, and other factors in motivating their firms' environmental actions. And these qualitative interviews also enabled us to pay closer attention to the role of firm size and industrial context in shaping managers' motivations in dealing with environmental problems.

The basic theory of general deterrence and its alternatives are discussed in a literature review in Thornton, Gunningham, and Kagan (2005) and are omitted here for the sake of brevity.

\section{METHODOLOGY}

We conducted in-depth telephone interviews of officials responsible for environmental compliance in a sample of thirty-five chemical and electroplating companies in two states (Washington and Ohio). ${ }^{2}$ These two industries were selected for more intensive study from the eight industries that were the focus of our earlier survey research (Thornton, Gunninhgam \& Kagan 2005), and were chosen because (1) they both have had substantial adverse environmental impacts, and (2) they varied most strikingly by average size and sophistication of firm, from small (electroplating) to larger (chemicals). We asked open-ended questions designed to assess the relative salience of (a) general deterrence messages, (b) other regulatory pressures (inspections, fear of private lawsuits), and (c) community, market-based, and reputationbased pressures, in shaping the facility's environmental behavior. We began by asking company officials and environmental managers to describe the most important environmental improvements they had made in recent years and the environmental actions they were most proud of, and why they had undertaken them (without prompting as to potential explanatory variables). Later in the interview we asked them to rate various factors, as causative influences. Lastly, interviewees were asked directly and explicitly for their view of the effect of deterrence on their company and industry's behavior.

When coding interviews, the questions were divided into four areas: (a) respondents' theories of how and why the industry had improved (Q1), (b) respondents explanations of why their firm had undertaken particular environmental actions $(\mathrm{Q} 2-4)$, (c) respondents general explanation of their environmental motivations (Q5-6), and (d) respondents responses to prompts 
about the importance of punishment and deterrence (Q7-9). We also drew on data gathered in our earlier 233 firm survey, particularly statistics relating to Colorado electroplaters and Kentucky chemical manufacturing and blending facilities.

The electroplating industry, in which companies generally are small, is difficult to monitor and hence an inherently difficult target for conventional deterrence-oriented regulatory strategies (Gunningham \& Sinclair 2002). Among our interviewees, company size ranged from 1 employee to 117 employees, with a median size of 32 employees. Partly because of the small size of most firms, the electroplating industry has not been the subject of sustained environmental campaigns by activist organizations or community groups, and "social license" pressures (Gunningham, Kagan \& Thornton 2004), have been muted. Yet precisely for this reason, the industry has at times been targeted by regulators as a high priority for enforcement action. Hence electroplaters, according to our earlier 233-firm, eight-industry survey (Thornton, Gunningham \& Kagan 2005), were especially likely to imagine that regulatory violations could lead to facility closure or to incarceration.

Chemical companies not only have been subject to substantial regulation, but also have often been under intense scrutiny from communities and local activist organizations. The industry contains both small and medium-sized enterprises (SMEs) and large corporations, enabling us to study both groups within the same industry sector. Chemicals firms in our sample ranged from 20 to 67,000 employees, but only two employed fewer than 100 people, and close to half employed more than 1,000 people. For present purposes, SMEs are defined as those with less than a thousand employees. Thus all electroplaters (the largest of whom had 117 employees) and half the chemical companies constituted our population of SMEs.

In the discussion below, we use the following codes for brevity: $\mathrm{E}=$ Electroplater, $\mathrm{C}=$ Chemicals, $\mathrm{O}=$ Ohio based, $\mathrm{W}=$ Washington based, $\mathrm{s}=$ small electroplater (under 30 employees), $1=$ larger electroplater (over 30 employees, in effect, SMEs), $\mathbf{S}=$ Small or Medium-Sized chemicals enterprise (under 1,000 employees), $L=$ large chemicals enterprise (over 1,000 employees). The number at the end of the code is the identifier of the particular enterprise.

\section{CHANGE OVER TIME}

Our industry respondents were almost unanimous in asserting that the environmental performance of their industry had improved very substantially over the last ten to fifteen years. For example, EOl-5 recollected how his workplace "was a complete mess 17 years ago... we were accumulating waste under the decks and there was two feet of sludge under the floor from drips and spillage. It had to be seen to be believed." Other electroplaters, too, described a substantial shift from a "dump and drain" mentality ("if you had to get rid of something you just dumped it" EWl-12) to a more responsible 
approach, involving use of fewer, and less toxic chemicals, reduced water consumption, reuse and recycling, and disposal only to prescribed facilities. ${ }^{3}$

For the chemical industry, the defining "wake up call" for many large companies was the environmental disaster at the Union Carbide plant at Bhopal in India, which killed an estimated 2,000-3,000 people in 1984 (Shrivastava 1992). This prompted collective action by chemical companies internationally, most prominently the development of Responsible Care, a management-system-based, self-regulatory program for curbing environmental hazards (Gunningham \& Grabosky 1998: chap. 4). Many of our respondents also identified a range of much more recent changes in attitudes and outcomes, especially in reducing the amount of waste generated and disposed of, and in curbing emissions. ${ }^{4}$

In both sectors, far more complex than determining whether the industry has substantially improved its environmental performance is determining precisely why it has done so. The motivational jigsaw that we attempted to piece together from our interview data suggests that different factors were at work in the two sectors and that, particularly within the chemical industry, there were further differences between large corporations and SMEs. For heuristic purposes, we examine these motivators under a number of discrete categories below, first for electroplaters, then for chemical firms, and explore the interaction among those categories in the subsequent discussion.

\section{THE ELECTROPLATING INDUSTRY: RESISTANCE IS FUTILE}

The seventeen electroplaters in our sample, as noted, were almost entirely small (under thirty employees) or medium-sized enterprises. Only four had more than 100 employees and more than a single location; many had less than fifty, and some less than five.

\section{A. LEGAL INCENTIVES}

All electroplaters unequivocally attributed the markedly improved environmental performance of the industry to the effects of regulation and/or enforcement. However, their responses did not clearly untangle the relative importance of regulations' normative message from the threat or actuality of enforcement. Nor was the relative salience of general deterrence versus specific deterrence entirely clear. But as we will see, regulation permeated respondents' decisionmaking process and shaped their options in taken-for-granted ways, generating a perception that, as the Borg in Star Trek put it: "Resistance is futile."

\section{Legal Sanctions}

For most electroplaters, the specter of legal sanctions for non-compliance was never far from their minds. ${ }^{6}$ Ninety percent believed that the threat of 
fines and jail or prison sentences was a powerful motivator of environmental action for their industry. Almost half (eight out of seventeen) of electroplating companies mentioned that their firm had previously been the subject of violations, fines, jail sentences, or threats of facility closure. And almost half, when explaining why they had undertaken an important environmental measure, described a fine or prison sentence that had occurred at the company (specific deterrence 24 percent), a fine or prison sentence that had occurred at another company (general deterrence 12 percent), or mentioned that the action had been taken to avoid a fine or prison sentence (12 percent). According to EOl-9, "Monetarily, companies have been hesitant to install treatment equipment that was required to meet the regulations. The financial burden was substantial'what's in it for me?' The answer was 'if you don't, you get fined or sent to jail'."

I ain't never been fined but ... It's pretty easy in a business like this for them to detect things in the water. Especially where I'm the only one in this county, you know, that has the chemicals that I have. And the trouble with the fines are ... Like I said, I never had one, but the place I worked at, they had a couple. And they seem to get larger, you know, for the same thing. They keep raising it. I think more or less to make you want to do something to correct it ... Being a small business, I can't afford to be fined you know. I make it from one month to the next. (EWs-14)

The fear of fines in turn was often used to bring about internal changes within the firm. As one owner put it to his workforce: "If we get a fine your raise is gone-there's a direct relationship. It's a good way to make it hit home" (EOl-4). EWl-5, when asked, "How were you able to convince the owner to spend on environment?" replied, "Fear basically. He decided to go along with it when he found out that he could get fined for not dealing with the situation." Indeed, there was almost a sense of inevitability about being penalized for non-compliance-a sense that in the long run, you simply could not get away with it.

Significantly, the size of these "inevitable" penalties was seen as sufficient to result in facility closure. Sixty percent of electroplaters interviewed felt there were only two choices: comply or be closed down, and 35 percent mentioned at least one specific example of an electroplating company that had gone out of business either trying to keep up with the regulations, or because of penalties imposed by the regulations. Typically, EOl-9 told us: "I've worked for a number of companies. The ones who were not serious about protecting the environment are no longer in business. Either they couldn't withstand the regulatory burden or they got closed down."

\section{Regulation and Implicit Deterrence}

Although the threat of legal sanctions lurks in the background, for most facilities in our sample it was the direct impact of regulations themselves that was the immediate driver of their environmental behavior, as the following responses make clear: 
We had to do it [put in an air purification system]-it was the law. (EWs-6)

Regulation was the driving force and we just implemented it. (EOI-3)

Everything we've done we've done because of regulations coming aboard or those already there so we could meet them easier. (EOs-11)

And EWs-14 summarized the incremental but seemingly inexorable nature of the regulatory process as follows:

When I first went to work in this trade I didn't even know what the EPA was, and then all of a sudden I started hearing a little bit about them, and the next thing I know they start coming around the place that I worked. Maybe once a year they'd come along. They didn't come around too often. Then pretty soon they started coming up with regulations, you know. You can't discharge more than this. And, at first if you watched it you could stay within the limits pretty easily. But then they lowered the limits. It kept getting tougher and tougher.

Only three electroplaters reported having sought out ways to save money by making environmental improvements independent of regulation. The others in our sample reported taking environmental action only when regulation required them to do so. Many acknowledged that once they had responded to regulatory pressure by making environmental improvements, cost savings sometimes ensued. EWs-7 told us:

We get huge savings. We used to cool our tanks by water which we dumped in the city sewer. It's monitored. Then six or seven years ago a cooling tower was installed-we moved from 500,000 gallons to minimal water usage-the bill was $\$ 2,000-3,000$ per month now its $\$ 126$ a month. And we are recycling cooling water. . We made [the changes] because we were told to make them.

And EWs-14 (a one-person operation) described how he made savings on chemicals by rinsing over a rinse tank and then putting the rinse water back into the process. Asked whether he would have made those savings without the regulations, his response was: "Probably not. I wouldn't have been forced into doing what I'm doing, you see."

\section{Inspections}

Every electroplating facility was regularly inspected at least once a year: by the local sewer district if they discharged to the sewer, by the fire department, and by state and federal environmental agencies. And inspections (and the anticipation of future inspections) had a powerful influence on firm behavior. Whatever inspectors required, electroplaters seemingly implemented. EWs-2 told us:

They [EPA] came in and said we want this, this and this done. And they wanted to see the improvements.

They [the regulators] are making platers do things more ethical. Everything used to go down the drain... They made us put in a treatment system. Now we're careful not to have chemicals lying around. We're careful about drip and run off from tanks, and we make sure there's no spillage. We've improved because we are annually inspected. (EOS-1) 
For the most part, these responses suggest that inspections, with their implicit threat of specific deterrence, played a prominent role in decision making by making the need to comply appear inescapable. Indeed, our respondents' comments in the previous section about the importance of regulation must be read in a context in which once the regulation was in place, they believed they would be inspected, infractions would be detected, and powerful legal sanctions could well be imposed.

\section{The Legitimacy of Regulation}

Fear of legal enforcement and sanctions was not the only reason for compliance, our interviews indicated. Equally important, it appeared was that notwithstanding the high cost of compliance, most electroplating facilities thought that environmental regulations were legitimate. In fact, complaints about enforcement action tended to focus on the injustice of others not being penalized, or not being penalized harshly enough. None of our respondents denied that regulation was needed, and a number actively endorsed it. EWs-7 said:

There's been no opposition. Once it's presented to you that the air is not good for you, it's ludicrous to disagree... We didn't know any better fifteen years ago. We dumped it all ... It [regulation] has been a good thing.

Some 40 percent of respondents professed to make changes required by regulation simply because it was "the right thing to do." For example, EWl-12 asserted:

Above and beyond the cost savings, you do the best you can as a corporation to protect the environment and the community. We've all got to live here and breath the same air and share the same water.

Those who offered a civic responsibility explanation for their behavior tended to divide the world into two classes of people (good guys and bad guys), and they often talked pejoratively about the "bad guys" in the industry, who were commonly seen not just as immoral but as "stupid", incompetent, or irrational. Consistent with this civic responsibility theme, almost half of the electroplaters in our sample expressed support for cooperative regulatory styles, in which they were given information and technical advice to facilitate compliance and minimize compliance costs, virtually implying that coercion was unnecessary. For example, EWs-7 said:

Some people despise regulators. I can't agree. In our industry they work with me-they give us technical options and we decide which we go for... We work hand in hand ... Once we know it's hurting the environment, we'd don't do it.

For this respondent, complying with regulation, doing the right thing, and following the inspector's advice, were so closely connected that he found it difficult to disentangle their influence. Similarly for EOs-1: 
I don't know all the rules. I do what I think is right ... There is only so much you can learn. If someone comes in I say, "You'll find things that don't fit with the rulebook. Work with us to get into compliance."

This ethical concern for environmental performance and belief in the legitimacy of environmental regulation was reflected in compliant firms' attitudes toward firms who had a different stance. One company in our sample expressed the viewpoint that for many firms, compliance, or the appearance of compliance, was simply instrumental:

It's all about money. Most owners want to play the game to make a certain amount and then get out, with no concern for the employees' health and safety. Consequently, they want to scrimp on everything they can ... [They spend on environment] to stay in the good graces with the regulators ... to keep ' $\mathrm{em}$ away from us (EOl-5).

Perhaps understandably, therefore, many firms who supported regulation as "the right thing to do" wanted harsh punishment for recalcitrant firms that evaded the law or made no effort to comply. They often talked pejoratively about the "bad guys" in the industry, characterizing the latter not just as immoral but as "stupid," incompetent, or irrational.

\section{General Deterrence}

We can now return to our initial questions about the significance of "general deterrence" as a driver of environmental performance. General deterrence is premised on the notion that punishment of one enterprise will discourage others from engaging in similar proscribed conduct. In response to our specific prompts, however, eleven out of seventeen electroplaters indicated that general deterrence had been relatively unimportant in their decisions to take environmental action. One firm did say that news of legal sanctions against other firms had been a powerful motivator of its own environmental actions, and two facilities reported that it had led them to take a specific important environmental action. Thus EOl-5 described taking environmental action because of "fear-when we found we could get fined-someone at a company where a lot of us used to work was shackled [sent to jail]which scared our owner."

Although a majority of respondents indicated that "fear" inspired by general deterrence had not been a significant motivator, they did acknowledge that hearing of enforcement actions against others focused their attention on environmental issues. They described such cases as "head turners" and "keeping you on your toes"-comments that support the "reminder" effect of general deterrence noted in Thornton, Gunningham and Kagan (2005). But most facilities told us that although general deterrence messages might make them take another look at their own compliance systems, they very seldom made any changes as a result. Several reasons were cited: 
(i) They often heard about deterrence actions second or third-hand through word of mouth and lacked sufficiently reliable details to know what action on their part was appropriate.

(ii) Differences in the nature of the work companies did, or the size of the facilities, made comparisons difficult.

(iii) Those that were punished were seen as fundamentally unlike our respondents - as "bad guys" who flagrantly ignored the law.

Despite their rather muted endorsement of general deterrence, most electroplaters believed that without general enforcement and sanctions, the environmental performance of their industry would decay over time and that some fraction of companies (the "bad guys" or those who could not afford to comply) would stop complying. And while most respondents asserted that in the absence of enforcement they would continue to operate their treatment systems, they acknowledged that "little things," like completing hazardous materials labels, might not get done, and new environmental protection measures might not be initiated, at least where these were expensive. As EWS-6 put it: "I like to think we'd be smart enough to be prudent. But when it comes to writing the check for $\$ 80,000$ or $\$ 90,000$, you'd look at what some of the other people are doing"-a comment that speaks to the "reassurance" effect of general deterrence noted in Thornton, Gunningham, and Kagan (2005).

\section{B. ECONOMIC MOTIVATIONS}

While all electroplaters attributed improvements in the environmental performance of the industry to regulation, enforcement, or liability (the legal sphere), 44 percent of larger electroplaters (four from nine) also attributed improvements to economic incentives-although none of the smaller electroplaters did so. For example, when asked why things had improved, EWI-12 responded:

Regulations. You must meet them to stay in business, but also to conserve on basic commodities [water, materials]. There is a savings there to us. The push to conserve has occurred in the last fifteen years. Pressure on our bottom line. It [conservation] makes the bottom line look a little better.

For EOl-13 answered, "Why have things improved? For compliance reasons and to cut down on the cost of hazardous waste."

When explaining why they had taken environmental actions that they had listed as particularly important, 90 percent of Ohio facilities and 50 percent of Washington facilities, both large and small, attributed these actions partly to economic incentives. These tended to fall in one of two categories: taking action to achieve cost savings, and taking action in response to customers' concerns. In terms of the former, EOs-10's response was typical:

We are always doing preventive maintenance. It's crucially important in terms of the environment. Why wait until it breaks down? Then the whole system is down ... It saves money. 
In terms of customer concerns, some Ohio electroplaters, particularly those with aerospace or motor vehicle manufacturers as major customers, talked about supply chain effects: demands from large customers for good environmental performance, and in one case, influencing their own customers to improve their environmental behavior-as the following responses indicate:

We are indirectly affected [by environmental groups] through the large companies that use our services . . . because they are getting pressure from them [the environmental groups]. So that affects aerospace and defense, and we have to remove chrome and chrome products from our products. (EOl-8)

Obviously all our environmental information is public knowledge. Getting rid of something that's bad-that's good for our image. Bad news travels fast. If they [the city] puts your name in the paper as a bad guy. Our customers like that we are trying to stay environmentally sound. If not, customers worry that you'll go out of business ... We talked to the customers about cadmium, and most of the customers switched to another coating. (EOs-11)

Those in niche markets with sensitive supply-chain relations were most likely to experience customer pressure.

\section{The Limits of Economic Motivations}

Despite such economic incentives, respondents also identified a range of other circumstances in which the costs involved in making environmental improvements far exceeded any economic benefit to themselves-thus limiting how much they could voluntarily invest in environmental measures. So for EWs-6,

The state of technology makes it difficult to get some metals out [of our discharges]. Most shops can't reach the [regulatory] standard because the equipment and chemical stuff we use don't get us there. It would take research or very expensive equipment.

\section{EOl-8 reported,}

The biggest obstacle is cost. It's money all the time--the number one factor which makes us decide how well to comply. Our company spent over $\$ 1$ million upgrading between ' 93 and ' 95 to meet new regulations ... Cost is a great concern for a small company... It's highly competitive and not easy to raise prices.

Similarly, while, as noted above, customer concerns were at least a partial motivation for the environmental actions of some facilities (six from seventeen) that served environmentally sensitive industries, the majority of electroplaters did not think their environmental reputation offered any competitive advantage:

My customers aren't concerned ... Unless you're really bad, it's the quality of the product that counts. (EWs-2)

It's customer driven. They want speed of turnaround and quality and inexpensive. Typically the customer takes a visual look at the plating on the part. If you have a reputation for lousy jobs you don't last long. But environmental performance doesn't matter to them. (EOI-4) 


\section{Other Motivators}

While all electroplaters described legal motivations as important, and a significant proportion also referred to economic incentives, a third of Ohio electroplaters talked about the impact of environmental actions on the health and safety of employees as at least partially motivating their behavior. EO1-5 asked:

Who is going to work in two feet of sludge? As well as health problems that would accumulate with workers and the sick leave that we would end up having to pay.

In addition, a number of larger Ohio electroplaters (four out of five) mentioned the role management attitudes played in stimulating environmental actions. EOl-13 thought that the most important environmental action his company had taken was putting in place a full-time environmental coordinator. Why was this person hired? "It was just that new management came in and saw that it [environmental] was always on the back burner before. Where he came from they stayed fully in compliance." Similarly, EOl-3, who pointed to his facility's hazardous waste practices as its most important environmental actions, said they had undertaken them because "it saves us a lot of money" and because of "attitude - upper management involvement ... once upper management says yes, it gets followed." However, only four out of seventeen electroplaters mentioned management attitudes.

External pressure groups, such as environmental NGOs (local or national), and local community groups, were conspicuous by their absence or lack of influence in electroplating. Most respondents felt that they were too small to be of interest to such groups. As EWs-2 put it: "We're a small outfit so they don't mess with me." Only one respondent, quoted above, mentioned that environmental groups had affected their company's environmental performance through the pressure they exerted on large customers.

Nor did the majority of electroplaters see their general standing with the community as having more than marginal significance. "Reputation? It's part of the picture. You don't need your name in the paper. Is it a major issue? No" (EOl-9). Some saw it as of no importance whatsoever: "Reputation? No people don't know about it" (EWs-7); others as a cosmetic add on "if you are neat and organized, people see you care" (EOs-1) or, almost independent of environment decision-making, as part of good citizenship. However, four companies did express some concern about getting bad publicity, and a fifth wanted to be seen as "responsible." EOS-11 pointed out that "when they publish in the paper that you're investigated by the EPA, then you start losing customers" because "they worry that you'll go out of business."

\section{THE CHEMICAL INDUSTRY}

For the eighteen chemical companies whose managers we interviewed, the range of motivational drivers at play was much broader than in the case of 
electroplaters. And among chemical companies, there was a marked distinction in this regard between the responses of SMEs and large companies. While legal sanctions were regarded as important by the former, they had little impact on the latter. Large chemical firms reported that while regulations provided the baseline for their environmental activities, they usually went beyond compliance for reasons related primarily to risk management and to the perceived need to protect their reputation and maintain the trust of local communities.

\section{A. LEGAL INCENTIVES}

\section{Legal Sanctions}

Six out of nine chemical SMEs (less than 1,000 employees) reported that their behavior had been affected by fines or a jail sentence (either to their own firm, or more usually, to others) (Q7). Three out of nine chemical SMEs (about the same proportion as electroplaters) mentioned the possibility of being put out of business by regulatory sanctions, whereas only one large company did so. CWS-9 explained that, "Bigger fines have more of an impact [than jail terms] because they can put a small company like ours out of business. If it's a big company like [X], their legal department could stall the legal action for years. But that isn't an option for a smaller firm." CWS-7 said: "I believe the threat of going to jail is particularly powerful for our company because we actually saw someone go to jail... We had an environmental issue in the early 1990s where there was a felony and someone went to jail for what the EPA called a clandestine drum-washing operation" (CWS-9).

In contrast, most large chemical companies (six out of nine) did not believe that fines or deterrence had an important effect on environmental behavior. The following responses are typical:

It's more a reputational issue. There is public scrutiny if you are cited or fined. It impacts your ability to sell your products. In practice, the penalties aren't significant. COL-13

Fines aren't a driving force. They're minimal ... I've never seen any big ones. It's the publicity that's the concern. Because it implies that you are not running the plant well. The general public infers that you are doing things you shouldn't and they don't want you in their community. CWL-6

Some senior employees of large firms, however, were mindful that they might be held personally liable, and this seemingly reinforced their own commitment to compliance. CWL-17 told us:

I went to boot camp and they filled us in on all the new regulations we needed to be aware of. What they emphasized is that plant managers are ultimately responsible, whether they know about an infraction or not. They made it clear that pleading ignorance isn't a way out. 


\section{Regulation and Implicit Deterrence}

Like electroplaters, chemical industry SMEs often talked about regulations as driving behavior in and of themselves. Thus COS-3, when asked why his firm had undertaken major environmental improvements, observed: "We probably wouldn't have looked at it if we hadn't had the EPA regulations requiring us to report the waste." COL-18 told us:

I don't read about the amount of penalties. I am more concerned about the regulations that got mentioned and whether we are in compliance with those regulations.

Many of the smaller chemical companies had what might be termed a "compliance mentality," defining their environmental performance in terms of adherence to legal requirements.

Larger firms also took regulation seriously, and there were some issues where for them too, achieving compliance was the principal objective, but rather than adopting a "compliance mentality," they commonly went substantially beyond compliance, asserting, like COL-1, "Compliance is [only] the baseline." Here are some typical large chemical-company responses:

Regulation plays a minimal role. Typically we get inspected. They make recommendations. I'd guess $20 \%$ of our improvements are from recommendations - not requirements. Typically we do it for good relations with the regulators. They are relatively easy to accommodate. (CWL-6)

Did regulation play a role? Not really. We did fine when we implemented "Responsible Care". It meant that we were ahead of the regulatory curve. It meant that when a new rule came in and we looked at what we had to do we were often already doing it. It made the challenge of complying with new rules relatively easy to meet. (COL-8)

The most important thing is our relationship with our neighbors ... Methanol is an example. Its regulated as a volatile organic compound-we reduced [emissions] beyond what the regulations require because we recognize it's a toxic chemical so to address the concerns of neighbors and our own interest in improving local air quality. We focus on it because it's a toxic chemical we use in the largest quantity. (COL-13)

\section{Inspections}

As is implicit in the comments above, inspectors and inspections, our respondents reported, had relatively little impact on the behavior of chemical companies. Only one chemical company out of eighteen mentioned that inspections played a role in why it implemented specific environmental actions, whereas more than a third of electroplating companies specifically mentioned inspections as playing a role. As COL-1 put it:

Regulators? They are there, but they don't pressure us. We haven't had more than 2 or 3 minor notices of violation in the last ten years, but nothing material. They come up about once a year, but we don't get extra visits and we're not under the gun. 
COL-8 told us:

Inspections are something we embrace. Ten years ago, responses to having an inspector at your door varied from "oh no, he's here" to "hi, glad to see you." Now we see having an inspector come as an opportunity to build a relationship with the local folks. Having a strong relationship with local agencies is very important, so you can just call up if you identify a problem and say, this is happening, what are we going to do about it.

Whether this was also the case one or two decades ago, we cannot be sure. Some companies implied that they would not have achieved their current level of environmental performance had they not been subject to considerable levels of inspectoral scrutiny in the past, although they saw that as having coincided with prodding by the chemical industry trade association, which was galvanized into action by major incidents such as Bhopal and Love Canal.

\section{Legitimacy of Regulation}

All our respondents suggested that there was a high level of compliance with regulation in their industry. Some referred (in somewhat similar terms to electroplaters) to the moral legitimacy of regulation. For example, for CWL-5: "There are two types of people - the 'I'll get by and nobody will catch me type'-that wouldn't be tolerated in our company-and the 'right thing to do/keep in compliance' type." None criticized the need for regulation, and some recognized that it was desirable. One respondent said, "Regulation? We brought it on ourselves. Laws don't fall out of the sky. There were missiles [Bhopal] that prompted the regulations." COL-13 thought:

Government regulations are probably the cornerstone of it. And while sometimes we as an industry, and we as a company, don't see the scientific support for some of the regulations and feel the money could have been better spent, for the most part, these regulations have been very important in improving environmental performance.

\section{General Deterrence}

In describing why they had taken a particular environmental action, not a single chemical company mentioned that they were motivated by an enforcement action that occurred against another company. However, when specifically prompted ${ }^{8}$ and asked about the importance of deterrence, most SMEs (six out of nine) and one large company (of nine) felt that hearing about other companies being penalized was a motivator. The type of penalty was also influential for some. CWS-7 suggested, "Fines don't have that big an impact. However, jail is different because it affects individuals. No one wants to go to jail. I don't want to go to jail." However, most respondents suggested that general deterrence might have an impact upon them only if a firm "similar to us" was penalized. 
Most large chemical companies, on the other hand, reported being totally unconcerned with deterrence because they felt they were comfortably in compliance. For example, COL-1 noted,

Certainly upper management is cognizant of potential costs of fines, civil and criminal. They are quite well aware. But the record speaks for itself. We are not even close to that. You don't even think about that... And if you do Responsible Care properly, you can't miss raising the level of consciousness and doing things that maybe have not been done. That's far more important than the threat of prison.

And even firms (predominantly SMEs) who did feel that hearing about others being punished had some influence on their behavior did not place great weight on this as a motivating factor. As noted earlier (and again below), the regulations themselves were far more important, for reasons unrelated to general deterrence.

\section{B. ECONOMIC MOTIVATIONS}

The large majority of chemical companies responded to the economic incentives that regulation and liability rules themselves provided, by engaging in waste recycling, using less (and less harmful) chemicals, and investing in new production equipment that was simultaneously more efficient and less polluting. The driver for these changes was commonly not a perception of "win-win" opportunities in the abstract, but rather that regulation had substantially increased the costs of traditional (and more polluting) industry practices. For example, COS-4 described how they evolved a system that avoided flushing and cleaning a tank out every time they changed the color of the coatings they make. This had apparently reduced waste "from hundreds of tons of waste generated for processes to under fifty tons a year". The reason?:

Liability. Every time we generate waste we are responsible for it from cradle to grave. If you minimize it you take the liability away. It has taken us way beyond compliance ... and it saves unbelievable costs of disposal. We spent close to $\$ 500,000$ a year to collect and dispose but now it's less than $\$ 50,000$ dollars a year.

Because going beyond compliance often was expected to save them money, large chemical companies (and some SMEs) actively searched for such measures, suggesting a degree of forward thinking that contrasted sharply with the approach of most electroplaters. Here are two responses that illustrate the point:

Anything you are discarding hurts the bottom line and if you [minimize waste] you're not using as many of the bad chemicals. We've used elimination and substitution and achieved dramatic drops in the last ten years. Why? Disposal costs have clearly gone up, chemical costs have gone up. The general health of employees. (CWL-6)

If you do an emissions inventory-identify sources and attack it, it's cost effective. You control and recover products, or you benefit the environment and benefit us in other ways. If you reduce your impact on the environment there 
are less regulatory programs that affect you. You don't have to comply with more stringent requirements down the track. If you are putting in place new technology it makes sense to look at your emissions and design to minimize at the front end. You reduce your compliance footprint, you go beyond compliance, so you reduce your reporting requirements. That makes life much simpler. (CWS-5)

CWL-11 went further. Having developed a new process to meet tougher Californian standards, they discovered this made them considerably more efficient, and, in an attempt to leverage their $R \& D$, exported that practice to their plants in other states even though the latter did not require it. Others sought to use less toxic materials in order to lower their insurance costs.

\section{OTHER MOTIVATORS}

\section{Reputation and Publicity}

Larger firms feared the stigma associated with non-compliance, and the damage that adverse publicity might have for their corporate reputation, far more than potential legal punishment following inspections. CWL-6 summed this up as follows:

I don't believe fines are a driving force. They are typically minimal. The publicity is a driving force. It leads the general public to believe you're doing things you're not supposed to do. It opens the door for watchdog groups-you've flagged yourself.

In describing why the industry's environmental performance had improved (Q1), eight out of eighteen chemical companies mentioned reputation or publicity as playing an important role. Of these eight companies, six were large. In contrast, no electroplating facilities identified these factors as important. Similarly, reputation for compliance was not a major concern for small and medium-sized chemical companies, which had no consumer brand name to protect and whose emissions generally were below the threshold for reporting to the national toxic release inventory. As CWS-7 put it: "Nobody knows us so there isn't much of a reputation to preserve."

Among larger firms, maintaining the trust of the local community was commonly cited as a high priority, particularly by facility-level respondents. For example, for COL-2 it was "the people 300 yards outside the perimeter fence" who were their main concern. Thus for COL-1:

Everyone at the plant is very concerned about our neighbors. We strive our best not to do anything to draw complaints. We want to stay here and we want to be here for another hundred years. Since the plant is stuck in the middle of a city-we are three blocks from city hall-we don't need complaints. You do whatever you need to do to keep them happy. I don't want to have to explain to a mother down the street why her five-year-old is sick and that it's my fault.

Reputation-sensitive companies feared that negative publicity concerning environmental issues could threaten the very existence of the facility, since 
the community might successfully oppose or delay permit permissions, or otherwise block expansion plans, or proposed technological change at facility level. One way or another, these respondents believed, facilities whose existence was seen as illegitimate by the local community faced "being regulated to death."

In addition, chemical companies worried that negative publicity could erode a company's relationship with its customers, suppliers, and regulators, and thus its bottom-line. As COL-1 put it:

It's more what comes with the fine-the publicity-you potentially lose customers if they find that there has been a serious fine. Customers now more than ever want environmentally responsible suppliers-that's one of the questions they ask-and those things really can hurt a company... They realize they don't need the embarrassment and the media issues. The people at the top won't tolerate violations and potential litigation. It can be managed. You don't have to spend on lawyers to bail you out.

Interestingly, environmental groups, our responses indicated, had no significant influence on behavior for either smaller or larger enterprises. They were not seen as a threat. Small enterprises believed they were likely to go completely unnoticed by such groups. Large firms often took the view that they had nothing to fear: "They have no direct influence. If we are in or beyond compliance then what can they ask? And we keep low key" (COL-1). COL-2, however, offered a partial minority view: "Knowing we might have to answer to them and they might knock on our door influences our thinking and the way we design our operational systems."

\section{Management Style}

Management style and corporate values had a significant influence on the behavior of large companies in a way that was not apparent with SMEs. In describing why the industry's environmental performance had improved (Q1), seven out of eighteen chemical companies mentioned management commitment, attitude, or management systems as playing a role. In addition, half the large chemical facilities (five out of nine) mentioned the role of internal management attitudes (for example, considerations of internal corporate philosophy) in their decision to take particular environmental actions (Q2-4), whereas one of nine smaller chemical companies did so.

\section{Trade Association}

Approximately one-third of the chemical companies told us that participation in the American Chemical Council's Responsible Care program structured many of their environmental initiatives and was responsible for much of the industry's environmental improvement. According to COL-1: "The American Chemical Council has had a tremendous effect-not so much enlightening large firms - they were in line anyway and have the systems in 
place-but they got the smaller guys' levels of consciousness raised." Yet for the most part, only larger companies in our sample were members of Responsible Care. And separating the rhetoric from the reality was difficult. A number of companies began the interview by citing the virtues and influence of Responsible Care, but when asked about what drove specific environmental initiatives, Responsible Care was rarely mentioned.

\section{Supply Chain Pressure}

Small and medium-sized enterprises, but not large ones, spoke of pressures they experienced from their larger trading partners to improve their environmental performance. For example, COS-4 said: "Reputation is a significant concern. Our clients are the government and Boeing. Image is very important. We sell our products as environmentally friendly." Conversely, a number of the large companies in our sample spoke of monitoring the environmental practices of their smaller trading partners. Typically, COL-16 asserted that they

will not conduct business with companies who have questionable practices. We audit all our vendors who supply us with chemicals and verify to make sure they don't do anything questionable. Moreover, we audit our customers to make sure that the chemicals we produce don't end up in the wrong hands.

And CWL-5 told us: "There are certain companies we won't deal with because of their environmental policies_-because of the risk."

\section{DISCUSSION}

What do our findings suggest with respect to the basic research questions raised at the beginning of this article? In stimulating compliance by regulated businesses, how salient are the "explicit general deterrence" messages sent by formal legal sanctions against other firms, compared to (a) the "specific deterrence" engendered by inspections of and legal sanctions against the firm itself; and (b) the "implicit deterrence" message sent simply by the dissemination of governmental regulations? Compared to legal deterrence, how salient are other factors-such as the threat of informal economic and social sanctions, or normative commitments to compliance with laws and regulations - as stimuli for compliance efforts? And do motivations vary - depending for example, on the type and size of organization (Gray \& Scholz 1991), or the characteristics of particular industry sectors?

\section{Specific Deterrence}

Specific deterrence in its narrowest sense-previous legal sanctions against a company that incline it to make more strenuous efforts to avoid future penalties-had a significant impact on a substantial minority of companies 
in our sample. Twenty-four per cent (four out of seventeen) of electroplaters and 11 percent (one of nine) of chemical SMEs said that a legal penalty against their company in the past had influenced its subsequent environmental actions. But for the large chemical companies in our sample, who reported having had only minor violations over the last decade, specific deterrence was not a salient driver of environmental actions (Q2-4).

Specific deterrence in its broader sense also includes the impact of inspections (with their implicit threat of legal sanctions). For electroplaters, inspections played an important role, prompting them to undertake whatever action was required of them in the belief that further enforcement action, with potentially profound consequences, would have followed from continuing non-compliance. 9 Inspections also had an important "reminder function" for firms already inclined to comply. Again, however, chemical companies (except for one) said that inspections did not have a significant influence on them, since they claimed they were already in or "beyond" compliance.

\section{Explicit General Deterrence}

Knowledge about legal sanctions against other companies, according to our interviews, played only a very modest role in the case of electroplaters and an even smaller one for chemical companies. Only 12 percent of electroplaters (two out of seventeen) said a fine or prison sentence at another company had influenced specific environmental actions. Among chemical SMEs, no one identified an environmental action that occurred against another company as having influenced particular environmental actions in their facilities, and large chemical companies reported that they were not at all influenced by such considerations.

There seem to be three reasons why the impact of explicit general deterrence was small. First, companies had great difficulty comparing their own circumstances with those of the company that had been penalized, commonly dismissing the latter as irrelevant (see also Braithwaite \& Makkai 1991). Second, since most of our respondents claimed to be in compliance (or even beyond compliance), hearing about punishments against recalcitrants held little fear for them. Third, the type of penalty imposed was important; some respondents suggested that it was only hearing about someone in similar circumstances going to prison, rather than merely being fined, that would influence them.

However, as in the eight-industry survey reported in elsewhere in this issue (Thornton, Gunningham \& Kagan 2005), explicit general deterrence did play a significant reminder function for both electroplaters and chemical companies-prompting them to review their own operations and compliance routines. And explicit general deterrence also fulfilled a reassurance function. Many respondents believed that without effective enforcement, the overall environmental performance of the industry would decline over time, as compliant firms would lose confidence that there was a "level playing 
field" in terms of expenditures to meet environmental standards. Many respondents placed considerable emphasis on this function, as complaints about enforcement commonly focused on the injustice of others not being punished, or not being punished heavily enough.

\section{Implicit General Deterrence}

What we have called "implicit general deterrence"- the threat of legal sanctions implied by the mere promulgation or history of enforcement of laws and regulations in the contemporary United States-was much more salient for our respondents than either specific deterrence or explicit general deterrence. Electroplators and chemical SMEs saw legal punishment of serious violations as virtually inevitable, and compliance with regulations was regarded as mandatory. This sense of regulatory inevitability was reinforced by the widespread perception among respondents that it was firms "like theirs" who were most vulnerable to inspection and enforcement. ${ }^{10}$

Our interviews indicate that "implicit general deterrence" arises from the general history of a particular regulatory regime (in this case targeted enforcement over the previous decades). In these industries, inspection and enforcement activity have generated a "culture of compliance," such that it becomes almost unthinkable to regulatees that they would calculatedly (as opposed to inadvertently) break the law. Thus it was the regulations themselves (rather than hearing about enforcement actions against other firms) that had the most direct impact on behavior. Rather than simply providing a threat, the regulations (as well as inspections) act as a reminder to enterprises as to what is required of them. But that occurs against a backdrop where the common perception was that "you go out of business if you don't comply." Indeed, for many interviewees, the regulations had become so embedded in their culture that they exerted an almost unconscious influence on decision-making. Some respondents attributed legally required environmental steps at their facilities not to regulation but to the firms' environmental ethos, seemingly oblivious to the extent to which they operated in a thick regulatory soup which constrained many of their choices."

For large chemical manufacturers, however, the mechanisms that led to compliance were rather different. They took regulation for granted not because of the perceived inevitability of sanctions (that is, implicit general deterrence) but because they felt a failure to comply would send very undesirable signals to important stakeholders, triggering a variety of informal sanctions. Yet they recognized that legal requirements served as a moral barometer of acceptable behavior in the minds of their investors, employees, customers, and local governments, and hence they had to attend closely to legal compliance. Whether regulation would have a much greater role for large companies facing economic hard times, which are cash-strapped and short-term in their approach, we are unable to say. 


\section{Normative Factors}

Strikingly absent from our interviews were diatribes against regulation in general or the unreasonableness of particular regulatory demands. On the contrary, almost half the electroplaters and chemical companies in our sample professed to comply not for instrumental reasons (including deterrence) but rather because it was the "right thing to do." A substantial number of electroplaters, for example, indicated that, now being aware of the environmental consequences of their actions, a return to the egregious pollution of earlier decades was almost unthinkable, even in the absence of regulation.

Interviewees tended to divide the world into two types of people, "good guys" (like them) who obey the law voluntarily, and "bad guys" who do not. Two things followed from this. First, regulation served a reminder function as to what it meant to be a good guy: a predisposition to "do the right thing" was tightened or brought into focus by the introduction of specific regulation. Second, regulation, as noted earlier, served a reassurance function. Since they believed bad guys would cheat if possible and thereby gain an unfair business advantage, our respondents indicated that they would be far less inclined to voluntary compliance if others were perceived to be "getting away with it." This comports with research finding that voluntary compliance is likely to be greater where enterprises believe not only that the rules are fair but also that they are fairly applied (Burby \& Paterson 1993).

This "level playing field" argument was less common amongst larger chemical companies. Many of these respondents identified senior management commitment as a major reason for improved environmental performancewithout any intimation that this might be contingent on what others were doing. This is perhaps understandable, given the importance that they placed on protecting their "social license" (Gunningham, Kagan \& Thornton 2003), which they felt they needed to do irrespective of how others behaved. Yet they may have felt some assurance in that regard as a result of the Responsible Care program, which was regarded by many respondents as having sensitized not only large, but more recently, smaller companies to their environmental obligations.

Overall, our evidence concerning the salience of normative considerations casts doubt on the assumptions of explicit deterrence theory, at least with respect to the many enterprises who perceive themselves as "good guys." This group did not behave as amoral rational actors; they did not carefully weigh up and adjust their behavior to fluctuations in the chances of detection and likely penalties. Deterrence was important for electroplaters and smaller chemical companies, but primarily by reassuring them that "bad guys" would be caught.

\section{Social Pressures}

Informal pressure from local or national environmental groups was not reported to have much if any impact on the environmental behavior of 
smaller electroplaters or chemical companies. Such firms perceived themselves (accurately it would seem) as "beneath the radar" of community or environmental activists. Only a minority expressed any concern about adverse publicity.

In contrast, larger chemical corporations reported that social pressures, reputational concerns, and avoiding bad publicity were primary drivers of their environmental behavior. Regulation was important in this regard because of the stigma associated with being sanctioned. Violations of their "social license," these large enterprises believed, could damage their relationship with local communities and land-use authorities, resulting in serious economic damage such as difficulty in obtaining necessary approvals for plant expansion. This sensitivity among large chemical companies likely reflects not only their greater sophistication and visibility but also the history of the industry, which has experienced a number of dramatic, highly visible and serious environmental disasters, such as the Bhopal explosion and the Love Canal site contamination. Although they took place many years ago, these incidents were mentioned in a number of interviews, providing the chemical industry with direct intimations of what it means to lose (or almost lose) its social license. Thus, like nuclear power companies in the wake of the Three Mile Island incident, chemical companies feel themselves, in Joseph Rees's (1994) apt phrase, "hostages of each other."

\section{Economic Pressures}

Amongst electroplaters, 40 percent of larger facilities attributed improvements in industry environmental performance, in part, to economic incentives. In addition, 80 percent of all electroplaters attributed some particular environmental response actions, in part, to economic drivers. However, small electroplaters, when asked in broader terms about influences on their behavior, almost invariably identified regulation, not financial savings, as the principal driver of environmental improvements. For chemical companies, economic incentives were substantially more important, with 50 percent (nine out of eighteen) identifying this as an important motivator for environmental improvement in the industry. On closer scrutiny, however, most changes respondents described were driven by the desire to find more efficient ways of reducing the costs first imposed by regulation or liability risks.

Large chemical companies were distinctive in the extent to which they devoted energy to anticipating and finding ways to minimize regulatory compliance costs and as yet unregulated environmental risks. Thus their approach was not merely to comply, but to comply in the least-cost way, and ideally to save money by pollution prevention planning or other means. In contrast, few electroplaters perceived the possibility of "win-win" opportunities likely to result in both environmental improvement and economic benefit. They did not seek out such opportunities, viewing environmental 
performance as costly, not potentially profitable. Hence, in that sector, external pressures, particularly regulation, and to a lesser extent, the normative concern to "do the right thing" were the dominant drivers of environmental improvements.

In terms of economic incentives, supply chain pressure was important for those small electroplaters who dealt with large customers whose own environmental credentials were important to their business success and insisted that their smaller trading partners comply with specified environmental criteria. Outside of these circumstances however, electroplaters sold on price and quality alone, and their customers had no impact on their environmental behavior. In contrast, most small and medium-sized chemical companies experienced such pressures because their larger trading partners (primarily large chemical companies) were themselves vulnerable to environmental pressures.

\section{CONCLUSION}

In the United States, deterrence lies at the very heart of regulatory policy. and its enforcement. Yet according to the electroplating and chemical companies whose managers we interviewed, neither specific nor general deterrence played a major role in shaping corporate environmental behavior. Specific deterrence (as previous punishment) apparently did have a significant influence on the future compliance of those who were subject to it, but less than a third of respondents mentioned such influences. General deterrence was reported to have had only a very weak influence on the behavior of electroplaters, and an even weaker one on chemical companies. However, general deterrence, while not a primary motivating factor, did serve as a reminder to firms about issues that might otherwise not have gained their attention (even though it rarely influenced their actions) and as a reassurance that non-compliant competitors were not "getting away with it" while our respondents spent money and energy on costly compliance measures.

Of far greater importance in motivating management was what we term "implicit general deterrence." We were struck by how many of our respondents in small and medium-sized companies did not calculate the likelihood of detection or the severity of punishment in the ways predicted by deterrence theorists. Instead they appeared to use a general rule of thumb: if you violate the regulations, you will eventually get caught, the penalty could put you out of business, and resistance is futile. Sustained inspection and enforcement activity seems to have inculcated a "culture of compliance." Consequently, the regulations themselves, not the fear of enforcement action, currently have the strongest impact on behavior. Rather than simply providing a threat, regulations and inspections acted as a reminder or guide to enterprises as to what was required of them. 
Moreover, instrumental considerations, even in the more complex form of implicit general deterrence, were not the only source of compliance-related action. Almost half of our respondents also provided a range of normative explanations for why they complied. Many thought of themselves as "good guys," complying with environmental regulation because it was the right thing to do. However, they struggled to disentangle normative from instrumental motivations, and wrestled with the temptation to backslide when environmental improvements proved very expensive. Many acknowledged that in the absence of regulation, it is questionable whether many firms' current good intentions would continue indefinitely to maintain good environmental practice throughout the industry.

Deterrence was of far greater concern to SMEs than it was to large ones. For major firms in the environmentally sensitive chemical industry, regulation and its enforcement was said to serve only "as a baseline." Most claimed they went beyond compliance in various ways for reasons that related to risk management and the perceived need to protect their social license. Crucial in this regard was maintaining the trust and support of local communities, avoiding the attention of environmental groups and other potentially critical stakeholders, and preserving the company's reputation as an environmentally responsible entity. Hence, large firms proactively sought out solutions that substantially mitigated regulatory compliance costs (and occasionally even saved money overall) in ways that boundedly rational small companies, particularly electroplaters, did not.

In sum, across all types of firms, there was little support in our interview data for models of business firms as "amoral calculators" who carefully weigh the certainty and severity of sanctions, as in standard deterrence theory. Regulation "works" through a complex mixture of pressures, fear, and normative duty. And context affects the causal weight of each element in that mixture: electroplaters responded very differently to various external drivers than did chemical companies, and even within the latter, small and medium-sized companies were influenced by substantially different considerations than were large companies. Precisely how the various motivational strands play out depends not only on the size and sophistication of regulated companies, but on the enforcement history and the characteristics of the industry sector within which they are located.

NEIL GUNNINGHAM holds professorial research appointments in the Regulatory Institutions Network, Research School of the Social Sciences, and in the School of Resources, Environment and Society, both at the Australian National University.

DOROTHY THORNTON holds a PhD in Health Services and Policy Analysis from the University of California, Berkeley and currently is a research associate in Berkeley's School of Public Health.

ROBERT A. Kagan is Professor of Political Science and Law at the University of California, Berkeley. 


\section{NOTES}

1. In addition, in some empirical studies, perceived informal sanctions seem to have a much stronger effect than formal sanctions (see Burby \& Paterson 1993: 753-72; Gray \& Scholz 1991: 185-214; Braithwaite \& Makkai 1991). Winter and May (2001: 675-98), found that normative and social motivations were as important in affecting compliance as are motivations based on expected utility and deterrence. For an excellent review of the economics literature see Cohen (1998).

2. With regard to the Ohio electroplaters, twenty-four were contacted; ten refused, nine agreed to participate, and in five cases, the researchers never connected with the environmental manager despite numerous attempts. For the Washington electroplaters, twenty-five companies were contacted: five did not meet our criteria, ten refused to participate, eight completed the interview, and in two cases, it proved too difficult to connect with the environmental manager. For the Washington chemical companies, thirty companies were contacted; seven did not meet our criteria, seven refused, nine participated, and in seven cases it proved too difficult to connect with the environmental manager. For the Ohio chemical companies, twenty-eight companies were contacted: eight did not meet our criteria, nine completed the interview, and eleven refused. The facilities were chosen to ensure that the sample included respondents from urban areas (Seattle and Spokane in Washington, Cleveland and Cincinnati in Ohio as well as rural areas; companies that operated a number of facilities in a number of states as well as those that operated only a single facility; and companies that ranged significantly in size from mom-and-pop operations to multinationals. Response rates were 40 percent $(8 /(25-5))$ for Washington electroplaters, and 38 percent $(9 /(24))$ for Ohio electroplaters. The most common reason given for non-response was lack of time to participate in a one-hour interview. Response rates were 39 percent $(9 /(30-7))$ for WA chemical companies and 45 percent for $\mathrm{OH}$ chemical companies $(9 /(28-8))$.

The non-respondents do not appear to have been disproportionately "bad apples;" nor were the respondents disproportionately "good apples." Using the EPA's "ECHO" online data set (http://www.epa.gov/echo/compliance_report.html), we found that in 2002-03, the average "quarters in noncompliance" (according to government inspectors) for electroplaters in our Washington sample was 1.38; for Washington electroplaters who declined to participate, the figure was 1.25, slightly less. We also compared electroplaters in our Ohio sample with all Ohio electroplaters in the EPA database, and the average quarters in non-compliance for both groups were virtually equal. Respondents in Washington more often were larger firms than were non-respondents (which nevertheless were slightly larger, on average, than the industry norm). But in Ohio respondents were about the same size, on average, as the industry norm, according to the EPA data set.

3. For a description of a 1999 EPA-supported benchmarking report that surveyed the range of environmental performance for the electroplating industry see Benchmarking Environmental Performance in the Strategic Goals Program (available at http://www.sectorstar.org/sector/MetalFinishing/index.cfm).

4. The substantial improvement in the environmental performance of chemicals industry is also supported by hard data. See annual Toxic Release Inventory data relating to the chemical industry reported annually on the American Chemicals Council website, http://www.americanchemistry.com.

5. See Startrek, The Next Generation, http://www.startrek.com/startrek/view/ series/TNG/.

6. Thornton, Gunningham, and Kagan (2005) found that electroplaters were likely to assess the probability that fines might lead to facility closure, as far higher than those of other sectors and that they had a much higher risk perception that an owner/operator would be incarcerated for a serious offence. 
7. Of course, water, sewer, and waste disposal charges may have increased not only because of market forces, but also as a result of regulations affecting water suppliers, sewer treatment plants, and waste disposal facilities.

8. "Particular environmental actions" refer to respondents' answers to Q2-4, which asked which environmental actions they were proudest of, and which were most important; these questions or follow-ups did not prompt respondents to consider the role of deterrence. "Prompted" questions regarding deterrence, on the other hand, refer to respondent's answers to Q7-9, in which they were specifically asked to address issues of deterrence.

9. The finding that inspections alone (without some significant form of enforcement activity) influenced compliance levels seems contrary to Gray and Scholz's (1991) findings (based on detailed statistical analysis with large samples). However, our finding must be interpreted in the broader context of a high level of enforcement in the electroplating industry in the past, which had given rise to a pervasive belief in the inevitability of enforcement action and the assumption that "you either comply or they shut you down."

10. Large firms believed that small firms were "getting away with it" while they themselves were not, while the converse was the perception of small enterprises.

11. COS-3 attributed her firm's improved environmental performance to an ethical commitment and to the influence of the American Chemical Council's Responsible Care voluntary initiative. However, her firm's most important environmental actions seemed to be shaped by neither of these considerations but rather, albeit subtly and indirectly, by regulation. Thus waste reduction and recycling, avoiding groundwater contamination, and containment of storage tanks were identified as the firm's most important environmental priorities. But in each case, although our respondent did not point to this, the firm's actions had been influenced by regulation. Waste, she acknowledged, "had to be reported to EPA" and their waste-reduction initiatives coincided with changes in EPA rulc-making. Moreover, the consequences of groundwater contamination were expensive precisely because regulation made them so. And notwithstanding our respondent's assertion that "the regulations had no relevance" to her firm's storage tanks initiative, that initiative also coincided with the underground storage tank (UST) regulations' requirement to complete a major upgrade over a ten-year period. Similarly, "In my three years I haven't seen an authority figure," asserted EOS-1 when asked about the impact of regulation. But he then went on to mention that "the city guy [the sewer authority] comes around once a month but not others. He keeps track and does a one-year write up and looks at everything. And the fire department comes once a year, but that's it."

\section{REFERENCES}

Becker, Gary S. (1968) "Crime and Punishment: An Economic Approach," Journal of Political Economy 76: 169-217.

Braithwaite, John, and Toni Makkai (1991) "Testing an Expected Utility Model of Corporate Deterrence" Law and Society Review 25: 7-40.

Burby, Raymond J., and Robert G. Paterson (1993) "Improving Compliance with State Environmental Regulations," Journal of Policy Analysis and Mamagement 12: 753-72.

Cohen, Mark A. (1998) Monitoring and Enforcement of Environmental Policy. Nashville, Tenn.: Owen Graduate School of Management, Vanderbilt University. Available at http://www.worldbank.org/nipr/work_paper/cohen/ (accessed 28 July 2004).

Grasmick, Harold G., and Robert J. Bursik Jr. (1990) "Conscience, Significant Others, and Rational Choice: Extending the Deterrence Model," Law \& Society Review 24: 837-61. 
Gray, Wayne B., and John T. Scholz (1991) "Analyzing the Equity and Efficiency of OSHA Enforcement," Law and Policy 13: 185-214.

Gunningham, Neil A., and Peter Grabosky (1998) Smart Regulation: Designing Environmental Policy. Oxford: Oxford Univ. Press.

Gunningham, Neil A., and Darren Sinclair (2002) Leaders and Laggards: Next Generation Environmental Policy. Sheffield, UK: Greenleaf Publishing.

Gunningham, Neil A., Robert A. Kagan, and Dorothy Thornton (2003) Shades of Green: Business, Regulation, and Environment. Stanford, Calif.: Stanford Univ. Press.

Gunningham, Neil A., Robert A. Kagan, and Dorothy Thornton (2004) "Social License and Environment Protection: Why Businesses Go Beyond Compliance," Law \& Social Inquiry 29(2): 307-41.

Kagan, Robert A., and John T. Sholz (1984) "The Criminology of the Corporation and Regulatory Enforcement Styles." In Enforcing Regulation, edited by K. Hawkins \& J. M. Thomas. Boston: Kluwer Academic Publishers.

Kagan, Robert A. (2002) Adversarial Legalism; The American Way of Law. Cambridge, Mass.: Harvard Univ. Press.

Miller, J. L., and Andy B. Anderson (1986) "Updating the Deterrence Doctrine," Journal of Criminal Law and Criminology 77: 418-38.

Organization for Economic Cooperation and Development (OECD) (2000) Reducing the Risk of Policy Failure: Challenges for Regulatory Compliance. OECD Working Paper No 77, appendix 1. Paris: OECD.

Rees, Joseph V. (1994) Hostages to Each Other: The Transformation of Nuclear Safety Chicago: Univ. of Chicago Press.

Regans, James L., Barry J. Seldon, and Euel Elliott (1997) "Modeling Compliance to Environmental Regulation: Evidence from Manufacturing Industries," Journal of Policy Modeling 19(6): 683-96.

Shrivastava, Paul (1992) Bhopal: Anatomy of a Disaster. 2d ed. London: Chapman.

Simpson, Sally S. (1990) Corporate Crime, Law and Social Control, Cambridge: Cambridge Univ. Press.

Stigler, George J. (1970) "The Optimum Enforcement of Laws," Journal of Political Economy 78: 526-36.

Thornton, Dorothy, Neil A. Gunningham, and Robert A. Kagan (2005) "General Deterrence and Corporate Environmental Behavior," Law and Policy 27: 262-88.

Tyler, Tom R. (1990) Why People Obey the Law. New Haven, Conn.: Yale Univ. Press.

Vandenbergh, M. (2003) "Beyond Elegance: A Testable Typology of Social Norms in Corporate Environmental Compliance," Stanford Environmental Law Journal 22: $55-144$.

Whittington, Richard (1993) What is Strategy - and Does it Matter? London: Routledge.

Winter, Soren, and Peter J. May (2001) "Motivation for Compliance with Environmental Regulations," Journal of Policy Analysis and Management 20: 675-98. 